\title{
CONTRATAÇÃo PÚBLICA: ANÁLISE DO PLANEJAMENTO, ADEQUAÇÃo DO OBJETO E AQUISIÇÃO ECOLÓGICA.
}

Pedro Durão ${ }^{1}$

\section{RESUMO}

O presente trabalho versa sobre o conteúdo da contratação pública a respeito do direito positivo, com a finalidade de traçar seus aspectos singulares e suas concepções distintivas, diante da necessidade de um eficaz planejamento, adequação dos produtos a sua utilidade, previsão orçamentária e a aquisição ecológica. O objetivo é enfrentar a primazia dos interesses da coletividade, partindo de peculiaridades conceituais em geral e sua tipologia construtiva, primadas pelas normas pertinentes e princípios. Utilizou-se o método hipotético dedutivo, a fim de alcançar a aplicação correta de valores para uma melhor interpretação da espécie, com vistas a maior eficiência da licitação pública. O resultado final do estudo mostra o necessário exame do sistema licitatório frente às normas e seus princípios para garantia de um melhor desempenho perante critérios mais justos e igualitários.

Palavras-chave: Contratação pública. Licitação. Planejamento. Previsibilidade orçamentária. Aquisição Sustentável.

\section{PUBLIC CONTRACTING: ANALYSIS OF THE PLANNING, FITNESS OF THE OBJECT AND ECOLOGICAL ACQUISITION.}

\begin{abstract}
The present work deals with the content of public contracting regarding positive law, with the purpose of tracing its unique aspects and its distinctive conceptions, in view of the need for effective planning, product suitability, budget forecasting and ecological acquisition. The objective is to face the primacy of the interests of the collectivity, starting from conceptual peculiarities in general and its constructive typology, preceded by pertinent norms and principles. The hypothetical deductive method was used in order to achieve the correct application of values for a better interpretation of the species, in order to increase the efficiency of public bidding. The final result of the study shows the necessary examination of the bidding system against the norms and its principles to guarantee a better performance against fair and egalitarian criteria.
\end{abstract}

Keywords: Public Contracting. Bidding. Planning. Budget predictability. Sustainable Procurement.

\section{INTRODUÇÃO}

Diante do tema: Direito, Cidade Sustentável e Diversidade Cultural, proposto pelo XXVII Encontro Nacional do Conselho Nacional de Pesquisa e Pós-graduação em Direito (CONPEDI), a ser realizado em Salvador/BA, concentramos o nosso campo de estudo no

\footnotetext{
${ }^{1}$ Professor Adjunto da Universidade Federal de Sergipe. Docente da Graduação em Direito e do Programa de Pós-Graduação da UFS. Mestre e Doutor em Direito. Pesquisador e Procurador do Estado. Email: pedro.durao@apese.org.br
} 
âmbito do Direito Administrativo e Gestão Pública, especificamente sobre a aquisição pública e sua interdisciplinaridade.

O presente estudo aborda o conteúdo técnico-jurídico da contratação pública, numa tentativa de traçar suas peculiaridades em uma abordagem crítica com o ensejo de revisitar suas bases teóricas e dogmáticas. Afinada com essa aspiração, o nosso escopo centrar-se-á na abordagem do planejamento ante a adequação dos produtos a serem adquiridos, previsibilidade orçamentária e a compra ecológica, na experiência inspiradora de doutrinadores brasileiros, como também, em alguns estudiosos no direito alienígena.

Enfrenta-se a primazia do planejamento em atender os interesses da coletividade e os direitos fundamentais, partindo do princípio de Estado Democrático de Direito e as peculiaridades conceituais e distintivas em geral, percebendo a real necessidade de entender sua tipologia construtiva, primado pelas normas e seus princípios, estes que se transformaram na base principal de todo o ordenamento jurídico.

Utilizou-se o método hipotético dedutivo, a fim de alcançar a aplicação correta de valores, por consequência proporcionar uma melhor interpretação da espécie, pelo qual a aquisição ecológica vem exercendo influência na gestão pública e na formação do atual direito administrativo. Feito isso, se pretende um exame do sistema frente às normas constitucionais e infralegais, formando uma realidade integradora para depois confrontar com a sua perspectiva pragmática.

O texto, naturalmente, não esgota a matéria. É, portanto, mero ponto de partida.

\section{NECESSIDADE DE UM BOM PLANEJAMENTO}

O Planejamento é palavra de relevância e um dos pontos mais importantes para o êxito da licitação em que se realizam os trabalhos de preparação das etapas que se sucederão. Seu objetivo é se antecipar ao que vai ocorrer para a contratação pública. Prevendo o caminho a ser seguido, se espera alcançar um melhor resultado em menor tempo, com mínimo de gastos possíveis, compatibilizando meios e minimizando os riscos.

É um verdadeiro exame racional antecipado da cronologia sucessiva da licitação, com fins de estabelecimento do objeto com sua especificação e quantidade, preço de mercado, do pressuposto utilizado e, também, as condições de utilização e armazenamento que se incluirão no futuro contrato. A sistemática da compra pública segue da etapa interna do planejamento para as etapas externas designadas para cada procedimento conforme os preceitos legais estabelecidos. 
O planejamento deve ter especial atenção na definição detalhada da licitação para definir prazos, critérios claros de julgamento, condições aos licitantes, determinando permissões e licenças requeridas, formas de pagamento, eventuais ajustes e outras indicações obrigatórias, designando os elementos decisivos e essenciais à elaboração do edital. Tudo isso se racionaliza para evitar imprevistos ou eventuais óbices, determinando as características precisas do objeto nos trâmites licitatórios.

Não basta seguir simplesmente o que dizem as normas licitatórias. ${ }^{2}$ É importante obedecer ao rito estabelecido para cada modalidade pensando em fazer valer as exigências legais com clareza e precisão, sem que estas sejam excessivas e desnecessárias. Por isso, o estudo prévio de todas as suas nuances e dos possíveis infortúnios eleva sobremodo as chances de sucesso da licitação, ao passo em que se analisará a situação atual, definindo os detalhes da contratação desejada.

Daí surge uma pergunta: Mas o que seria um bom planejamento? Será aquele capaz de representar um exame pormenorizado realizado de antemão ao feito licitatório, no sentido de impor rapidez para que se tenha agilidade na contratação, precisão na utilização dos meios adequados à melhor execução possível, e rendimento para otimização dos resultados da Administração Pública. De fato, tudo dependerá de um planejamento ${ }^{3}$ bem estruturado para uma licitação exitosa.

Além disso, se buscam as exigências compatíveis a escolha do melhor contratante, em caminhos pré-definidos e simplificados em favor da eficiência. Tal medida reflete o grau de organização da entidade patrocinadora da compra e o preparo de seus funcionários, já que a regra é a morosidade dos certames e a percepção de falhas que comprometem a programação realizada.

Não é à toa que os certames licitatórios costumam ser lentos, muitas vezes, cercados de inúmeros recursos administrativos e de demandas jurídicas, encarecendo os custos que são pagos pela população.

É razoável pensar criteriosamente na execução das licitações, antevendo proativamente infortúnios ou excessos que provoquem sua nulidade ou ações judiciais que influiriam em seu atraso. O minucioso planejamento pretende também adoção de medidas que evitem alegação de urgência para justificar ausência de procedimentos indevidos ou excesso de contratações diretas indevidas.

2 Ampliar os problemas da preparação do edital e o contrato em Gordillo (2009, p. 22).

3 Ampliar a relevância do planejamento em Trindade Júnior (2010). 
Para efetuar um trabalho eficaz é necessária uma equipe de funcionários com sólida preparação técnica, conhecimento e experiência, remunerados de forma compatível com seu grau de qualificação. Na prática, ao revés, ocorre que na maioria das vezes por não adotar o critério técnico na escolha daqueles que trabalham na licitação, elegem, por vezes, aqueles que viabilizam interesses alheios, nomeados politicamente em cargos em comissão, não obstante a estrutura existente com vistas a agir nos parâmetros morais.

Deve-se analisar o todo, antecipando a condução dos procedimentos. ${ }^{4}$ Isso significa estabelecer o porquê e o que será feito, quem e quando se fará, como e onde ocorrerá a licitação para fins de não ser surpreendido com incertezas ou eventuais óbices, viabilizando o mínimo de gastos possíveis, no menor espaço de tempo. Seria prever o objeto e sua finalidade, a autoridade competente, a cronologia dos eventos, as nuances de forma, a localidade e o tempo provável em que ela se realizará.

Outra medida a considerar seria a informação generalizada de dados em base única permitindo a visibilidade de padrões de fornecedores e seus produtos. Buscar-se-ia, também, a coleta das necessidades de vários órgãos compatibilizando com uma central de compras para que fossem realizadas aquisições em conjunto. Tal medida permitiria a conjunção de esforços para levantamento de necessidades comuns de determinados órgãos em uma aquisição conjunta e programada, minimizando gastos com pessoal, preços, etc.

O ideal é realizar um estudo minucioso dos custos do processo licitatório. Mister se faz buscar um ponto de equilíbrio entre os custos e os recursos comprometidos, onde o custo ideal seria não incorrer em desperdícios nem em atrasos.

A argumentação traduz um melhor desempenho organizacional que permita diminuir incertezas e economizar custos e tempo em busca do fim desejado. Por isso se diz que o planejamento deve ser sistêmico, interativo e cíclico. De feito, deve-se pensar de modo produtivo, desde o nascimento da proposta de aquisição até a sua efetiva aquisição, sem esquecer-se dos critérios logísticos, como recebimento e armazenamento dos bens adquiridos, e ainda, da adequação dos produtos à utilidade, o próximo assunto a ser estudado.

\section{ADEQUAÇÃO DOS PRODUTOS A SUA UTILIDADE}

Não basta adquirir os produtos necessários à Administração Pública, é fundamental que se analise sua real utilidade ${ }^{5}$ para evitar sobras e desperdícios. O gestor público ao iniciar um procedimento de compras, além das preocupações legais, não deve se distanciar da ética,

\footnotetext{
${ }^{4}$ De igual forma diz Durão (2015, p. 117-119).
}

5 Ampliar em Dallari (2007, p. 3). 
primando pela conduta administrativa. Gere-se visando a melhor aplicação dos pressupostos com o menor custo possível, sem comprometer excessivamente a receita pública.

É imprescindível que todo órgão público possua uma comissão técnica específica, com o escopo de analisar a necessidade de adquirir determinado serviço ou produto, acompanhando, in loco, sua execução ou utilização. Isto não significa dizer que vai haver restrição de uso, mas a ampliação do controle, alcançando os resultados desejados, tanto no momento aquisitório, como na execução contratual, ${ }^{6}$ esta, por vezes, totalmente esquecida. Acontece que em grande parte das compras públicas não há acompanhamento destas fases, deixando o organismo público ao acaso do contratante.

A fiscalização é fundamental para detectar se os produtos/serviços adquiridos estão sendo devidamente utilizados, sem desvios ou má utilização, o que geraria, inevitavelmente, uma compra ineficaz com vinculação indevida de recursos, com gastos públicos que poderiam ser aplicados em outros fins.

$\mathrm{Na}$ aquisição de obras e serviços de engenharia deve se pensar em tudo, desde a abertura do processo até a efetiva contratação, estabelecendo critérios elaborativos de projetos básico e executivo, licenças ambientais, orçamento minucioso, para fins de maturação técnica na confecção do edital, publicação dos avisos, sessões da licitação, adjudicação e aceitação ou recusa do contratante. Ressalta-se a individualização do serviço, discriminando as etapas e métodos de sua execução para alcance do esperado resultado.

Desse modo, abaliza-se todo o ciclo de vida do serviço. Isto ocorreria, verbis gratia, em uma obra pública onde serão analisados itens como acabamento, estrutura, custos locais, mão de obra, tipo de solo e prazos de conclusão, em que para sua implementação são essenciais: o projeto básico, instalações especiais, aquisição de equipamentos e materiais, bem como, a execução e supervisão da obra pública. (ALTOUNIAN, 2009, p. 32).

Frise-se a título de ilustração que o estudo do prazo conclusivo pode ser extremamente fundamental para uma reparação ou construção de rodovia, em que haja previsão de fortes chuvas, onde encostas de proteção podem se romper pela erosão da água, danificando a estrada inacabada, com prejuízos incalculáveis, além de perda de logística (maquinário, material, etc). Cumpre ser proativo, e prever todas as hipóteses possíveis, pois daí advém pistas intransitáveis, influenciando e onerando o contrato, postergando o término da obra. 
Ao final é necessária a análise do setor de engenharia para possibilitar a reparação na citada rodovia. É importante o estudo do serviço a ser realizado, observando o tipo de material que esta sendo usado, comparando-se com outras obras que deram bons resultados, no que concerne às condições de tráfego, adotando providências no sentido de evitar avarias. Por outro lado, o que se vê é o poder público insistentemente reparando a mesma rodovia, em um espaço de tempo exíguo, por fragilidade do revestimento contratado e planejamento mal sucedido.

Tudo resulta de um plano de gerenciamento de projetos para acompanhamento de uma obra pública. Este deve conter as metas e diretrizes orçamentárias, plano diretor, como instrumento de políticas territorial e plano de saneamento. Observa-se, ainda, programa de obras, estudo de viabilidade técnica econômica, planejamento de recursos financeiros, atendendo as exigências fiscais para acompanhamento das etapas de licitação e da execução de construções públicas. ${ }^{7}$ (OLIVEIRA, 2010, p. 19-24).

É Importante analisar a adequação do produto à utilidade, verificando a composição de todos os custos e solicitando o montante de beneficio e de despesas indiretas, com a planilha de custos e serviços em um cronograma físico financeiro, e ainda, desenho e memorial descritivo do método e cálculo aplicado.

É fundamental a o desempenho do fiscal de obra que tem a função de controlar os serviços e equipamentos usados, atento ao uso do material, provimentos e recursos humanos, em conformidade com o que foi previsto na proposta inicial. (OLIVEIRA, 2010, p. 192-193).

A Administração Pública é obrigada a licitar nos moldes legais em vigor, com os rigores determinados pelo valor da obra. Tudo isso demanda tempo e ocupa servidores, enfim, envolve todo o aparato público para sua elaboração, fiscalização e concretização. É inegável que ela é entregue pela empresa contratada, sem que haja uma rígida fiscalização acerca do que se está utilizando; como, quem, onde e de que forma se realiza o serviço. Com a adequada fiscalização, evita-se a repetição do trabalho mal feito ou a contratação de outra empresa para o serviço.

Daí, a importância de um método de fiscalização, contextualizando a ideia de que o preço e qualidade devem andar pari passu, como se fossem inseparáveis. Estes são fatores primordiais para a consecução eficiente da utilização dos recursos públicos, tendo como objetivo a satisfação das necessidades imperiosas da sociedade. 
Apuram-se as prioridades coletivas, definindo um programa cronológico com levantamento da relação custo e beneficio em relação à quantidade útil do produto. Isso, porque não teria sentido comprar dez (10) ambulâncias para um vilarejo com cinquenta (50) pessoas, pois importaria em um estudo das deficiências públicas com mensuração dos benefícios oferecidos, utilizando-se da proporcionalidade de meios. Trata-se de uma verdadeira utopia quando em alguns momentos, tudo é efetuado de forma precipitada, sem apurar as particularidades em foco, no momento de contenção de despesas que passam as administrações públicas.

O gestor público também deve utilizar os meios adequados ao analisar o período e local de utilização do bem, examinando suas peculiaridades. Adequando o exemplo anterior, é imprescindível um estudo apurado de suas especificidades ao se adquirir ambulâncias para trafego por estradas danificadas e de acesso precário entre municípios distantes, posto que a exigência da durabilidade decerto seja bem maior em relação às estradas melhores, devido ao menor desgaste mecânico.

Tem-se, portanto, que estudar todos os aspectos para que não se adquira o produto somente pelo preço mais vantajoso, e depois despender altos valores com a sua manutenção, o que vai torná-lo mais oneroso no decorrer do tempo.

Assim, quanto à abordagem de custo, se deve analisar a durabilidade e a qualidade do produto. A propósito, quando se compra um produto " $Z$ " com menor valor de $\mathrm{R} \$ 2,00$ (dois reais), ao invés de comprar um produto " $\mathrm{Y}$ " que custa $\mathrm{R} \$ 3,00$ (três reais), este, porém, detentor de melhor qualidade e durabilidade, apesar do maior preço. Deve-se atentar no cálculo quanto à vida útil do bem e os atributos inerentes. É bem verdade que o produto "Y" no decorrer do consumo - vai se tornar mais barato do que o produto "Z", com preço inicial inferior.

Por isso, devem-se especificar todas as características necessárias ao bem desejado, com sua utilidade e qualidades essenciais. É sabido que todo trabalho que se precisa corrigir, não agrega valor, só gera custo. Portanto, as irregularidades devem ser eliminadas para se elevar a excelência. Ao se reduzir as incertezas, as necessidades de produtos que não acrescentam valor serão diminuídas. Todavia, essas inconstâncias somente serão excluídas se as funções operação, supervisão e gerenciamento estiverem funcionando em sua plenitude.

A criação de um método operacional de compras é primordial para obtenção da equação almejada na relação preço e qualidade. Desse modo, mensurado o uso de um bem ou serviço, pode-se reduzir os gastos evitando produtos desnecessários. Para isto, é bastante fazer 
um levantamento da necessidade em função do consumo, verificando a demanda passada e estimando uma possível futura. Enfim, as variáveis a serem trabalhadas para aquisição de um produto serão: preço, qualidade, consumo e utilidade.

Quando uma entidade pública efetua uma compra é essencial ter em mente um preço médio e o custo do produto. É comum que a Administração Pública compre sempre com valores mais elevados do que cidadãos e empresas privadas, algo que não deveria ocorrer, já que é imprescindível alcançar o custo médio de determinado produto.

Quando uma pessoa física compra um determinado produto, ela o faz sem saber se a empresa fabricante está com suas obrigações fiscais em dia. Compra porque a situação econômica financeira assim permite. Já, a entidade pública ao fazer a mesma aquisição tem que seguir as imposições legais que a obriga exigir a regularidade fiscal do fornecedor, perante órgãos de arrecadação da União, Estados ou Municípios, entre outros diversos encargos. Por isso, tudo deve ser pensado e computado para se alcançar o custo de adequação do produto à utilidade.

Esse controle permite uma racionalização do que se adquire, gerando um ganho de eficiência nas compras públicas, e consequente diminuição de gastos. Para isso, podem-se utilizar ferramentas de controle, tais como, análise de custo benefício, análise efetiva da aplicação de determinados produtos. Esta redução de custos permitirá uma maior disponibilidade de recursos para o desenvolvimento socioeconômico e a diminuição da desigualdade social.

Nesta linha de raciocínio, se utilizaria uma análise da utilidade do produto e suas peculiaridades. Por exemplo, na compra de um carro popular para rodar em estradas de chão, examinam-se todos os aspectos para não adquiri-lo só pelo preço, mesmo que seja aparentemente vantajoso, e depois empregar altos valores em sua manutenção, o que vai torná-lo muito mais caro no decorrer do tempo. Por isso, não compensa uma compra baseada somente no preço mais baixo, sem observância das particularidades do produto e de sua utilidade.

A finalidade da licitação é selecionar a proposta mais vantajosa colocada à disposição da Administração Pública, no sentido de não permitir o favorecimento ou facilidades escusas. Acontece que ela, na prática, compra produtos por valores mais alto que os encontrados no mercado, por vezes em descaso as regras orçamentárias estipuladas. Adiante se estudará a principal característica que envolve a previsão orçamentária. 


\section{PREVISIBILIDADE ORÇAMENTÁRIA}

Sempre que a Administração Pública adquire produtos e serviços, ela gasta recursos oriundos de arrecadação de tributos pagos pelos cidadãos. Esses recursos - que tem diversas finalidades, como aquisição de bens móveis e imóveis, ou ainda, contratação de serviços visam atender as necessidades coletivas pelo menor custo possível.

Inicialmente, para que se possa utilizar o recurso público na execução dos seus serviços, é necessário planejamento e a autorização legislativa. Assim, é criada uma lei orçamentária, onde são estimadas receitas e despesas para viabilizar as ações públicas, está intimamente ligada ao planejamento. Por sua vez, é imprescindível a capacitação de gestores financeiros ao propósito de identificar quem, quando, onde e como vai gastar o dinheiro público, de forma a garantir o equilíbrio financeiro, otimizando as contas públicas.

Maximizar recursos é reduzir custos. O poder de compra da Administração Pública deve ser voltado para o desempenho do que será adquirido, não bastando preocupar-se somente com a lisura no momento da utilização do recurso público. Seu emprego deve ser eficiente e eficaz, com capacidade de prover o desenvolvimento econômico social do Estado, com erradicação da pobreza e redução das desigualdades sociais.

O primeiro passo é o planejamento, com o exame da operação da despesa pública ${ }^{8}$ até o pagamento da contratação. Esta projeção possui pontos crucias que devem observados, tais como a necessidade da aquisição do bem ou serviço; a segurança de que vai haver o recurso orçamentário e financeiro. ${ }^{9}$ E esse pagamento será realizado dentro da programação estabelecida.

Todo órgão público deverá ter fluxo financeiro. Ele tem um orçamento ${ }^{\mathbf{1 0}}$ que autoriza despesa e estima receita, assim, a contratação se realiza baseada na autorização da despesa, não verificado se a receita está acompanhando esse gasto. Se um órgão pretende contratar a aquisição de bens ou serviços, ele deve assegurar esse recurso, com a saída do dinheiro público para pagamento do produto licitado.

A previsão orçamentária é feita tomando por base os gastos do ano anterior, e para subsidiar a elaboração orçamento mais realista, deve sempre rever as necessidades que

8 V. o conceito clássico de gasto público de Baleeiro (1977, p. 24): "aplicação de certa quantia, em dinheiro, por parte da autoridade ou agente público competente, dentro de uma autorização legislativa, para execução e fim a cargo do governo".

9 É inegável a ligação cruzada de matérias com o direito administrativo em Gordillo (2009, p. VIII-25).

10 Alerta Riveiro (1981, p. 513) sobre a organização de serviço público: "Desde o ponto de vista financeiro, o serviço não tem nenhuma singularidade. Os critérios necessários para seu financiamento estão incluídos no pressuposto geral de gastos da comunidade. Se ele obtém rendimentos, estes se confundem no conjunto de receitas orçamentárias, que vão servir de base para o conjunto de gastos." (Tradução própria). 
surgirão no decorrer do acompanhamento do orçamento anterior. Dentro dessa previsão ${ }^{11}$ se encontra o montante de receita a ser arrecadada em determinado período, objetivando cobrir as despesas estimadas.

A previsão de recursos deve seguir as normas e os procedimentos atinentes à matéria, observando as deliberações dos tribunais de contas, e ainda a previsão de receita e fixação de despesa. Esta deve ser assentada por área de interesse, seja educação, saúde, segurança e outros, para daí alocar as aquisições de produtos e serviços pertinentes, detalhando-as por elemento. (BEZERRA FILHO, 2007, p. 77).

Por parte da despesa pública, o organismo aplicará a quantia certa em favor da aquisição de um produto ou serviço, em um comprometimento orçamentário ${ }^{\mathbf{1 2}}$ para pagamento em favor do contratante selecionado na licitação. E não são poucas as formas violadoras que, se utilizados, impõem responsabilidade do agente, seja em suas cláusulas ou em qualquer condição instrumental que autorizem.

Observam-se defeitos graves que responsabilizam agentes públicos por desobediências aos ditames orçamentários. A ilegalidade que exsurge não se resume à inobservância das normas referentes à matéria, mas abrange a necessidade de atendimento a todos os princípios informadores da Administração Pública e aos elementos constitutivos das licitações públicas.

Nesse sentido, é frequente o desvio da finalidade de recursos alocados a estas áreas, onde o controle interno da fidelidade funcional far-se-á por meio de levantamentos, prestações ou tomadas de contas ${ }^{\mathbf{1 3}}$ de todos os responsáveis por bens ou valores políticos.

Indubitavelmente a despesa integra o orçamento para desígnio de suas funções elementares. Deve-se, portanto, analisar a sua correta aplicação em busca de harmonia e equilíbrio das receitas e despesas, evitando a malversação do erário. Até porque a despesa pública só pode ser realizada com autorização, na forma respeitante aos preceitos da Constituição Federal, implicando crime de responsabilidade às autoridades públicas que desobedecerem à restrição legal.

Saliente-se que o orçamento permite a visualização comparativa de receitas e despesas da Administração Pública em perfeita demonstração de organização e método. Nesse

11 Observe-se o que sustenta Rosa Júnior (1977, p. 23): “o exame do gasto público deve anteceder o estudo da receita pública, a diferença do que ocorre com o conceito econômico e privado, isto é, que o gasto deve ser realizado depois do cálculo dos rendimentos como ocorre normalmente com as empresas privadas".

12 O Brasil adotou a Lei de Responsabilidade Fiscal como um marco limite dos gastos de pessoal e a dívida pública nas esferas da União, Estados e Municípios. Cf. Lei complementar nº 101/2000. (BRASIL, 2018a).

13 Trata-se da interpretação de documentos e registros desde o ponto de vista técnico, legal e enquanto a princípios prestados pelo organismo, receptor do benefício, ao ente público outorgante. 
raciocínio, não podemos esquecer de que outros documentos, além do orçamento público, permitem visualização de parâmetros financeiros, assim como: balanço patrimonial, balanço da execução do orçamento, prestação de contas e outros.

O contrato público, ${ }^{14}$ por sua vez, caracterizar-se-ia, para a construção dessa obra, em um acordo no qual se dispusesse que sua edificação estaria a cargo do pagamento à outra parte. Como haveria a expressa contratação (haja vista ao ajuste de vontades opostas: construção de obra e pagamento) estar-se-ia diante de um verdadeiro contrato administrativo, em que a seleção das empresas construtoras será realizada sobre as regras licitatórias. ${ }^{\mathbf{1 5}}$

Ressalte-se que ninguém contrata para não cumprir o que convencionou. Os contratantes estão sujeitos às cláusulas do acordo firmado, e a este se submeterão em homenagem ao pacta sunt servanda, corolário das disposições observadas no ajuste. Como é sabido, o contrato administrativo tem um procedimento próprio para se inserir na regularidade administrativa que reclama o princípio da legalidade. Então, submeter-se-á o ente privado ao procedimento licitatório como meio hábil e legitimado, com o fito de manter o acordo firmado com a Administração Pública.

Outra razão é a necessidade de atrelamento da despesa pública à aquisição desejada para fins de efetiva prestação de contas às autoridades superiores ou aos tribunais de contas. ${ }^{\mathbf{1 6}}$ Importa saber que a autoridade administrativa não pode adquirir carteiras escolares (bens móveis) com a sobra de verba destinada à construção de escolas públicas (contratação de obras públicas), assim como, não se pode comprar merenda escolar (auxílio alimentos) com excedente de verba estipulada para aquisição de canetas (material de consumo). Ao gastar o dinheiro público, deve-se sempre atentar para as rubricas pelas quais estão dispostas no planejamento e a lei autorizativa orçamentária para aquele determinado objeto eleito, quer seja para compra de alimentos, cadeiras, canetas, entre outros, sob pena de responder pelo desvio de finalidade.

Um novo postulado brinda a democracia. É o orçamento participativo, realizado através de audiência pública, ${ }^{17}$ onde a sociedade pode sugerir as áreas de maior estrangulamento para maior destinação de recursos públicos, ouvindo os cidadãos e organizações representativas. Trata-se da participação popular na fiscalização e elaboração do

14 De feito Gordillo (1988, p. 17-18) afirma que os contratos administrativos têm primordialmente regime de direito público, diametralmente opostos aos contratos de administração do regime civil, todos sem renúncia aos princípios orientadores do Estado.

15 Assim ocorre no Brasil, onde o ente de natureza privada está obrigado a seguir as normas de licitação pública.

16 V. Orientações do Tribunal de Contas da União (TCU, 2010, p. 33).

17 Ampliar os procedimentos de audiência pública em Gordillo (2009, p. XI-1-11). 
orçamento onde se originam verbas para patrocinar a aquisição de produtos e serviços, através da licitação. Significa estabelecer diretrizes estratégicas para otimização do desempenho no médio e longo prazo na execução de programas em busca de resultados mais efetivos à sociedade, por seus cidadãos.

O que se deseja é o equilíbrio entre a receita e a despesa no exercício financeiro, já que não se pode gastar mais do que se tem, nem mesmo os organismos estatais. Daí a função prioritária do orçamento público na locação de recurso, em conformidade com os programas de governo para provisão de bens e serviços ajustando-se a distribuição de renda para fins estatais. Por isso, a necessidade de determinar diretrizes, traçar objetivos para alcançar as metas, através de programas que resultem na integração dos esforços governamentais. Isso significa estabelecer as demandas medindo-se o desempenho e custos em busca do resultado final para satisfação das necessidades das sociedades.

\section{AQUISIÇÃO ECOLÓGICA}

$\mathrm{Na}$ atualidade, observa-se uma mudança sensível no sistema ecológico mundial, capaz de comprometer os elementos essenciais para a sobrevivência do ser humano, tais como a defesa do ar, água e solo, bem como as espécies viventes do ecossistema. Essa desordem fere os direitos humanos do homem como direito à vida, ${ }^{18}$ à saúde e a um ambiente sustentável ${ }^{19}$ para gerações atuais e futuras. Devido à preocupação com o meio ambiente, ${ }^{20}$ esse assunto está ganhando repercussão em fóruns internacionais, meios de comunicação e nas inquietudes da sociedade devido ao iminente perigo de destruição da biosfera.

Somente após a segunda guerra mundial, ${ }^{21}$ falou-se em formação de consciência ambiental, $^{22}$ em ações políticas e jurídicas, iniciando-se, desse modo, a luta pela (re)construção do meio ambiente totalmente destruído pelas atrocidades e doenças peculiares da época.

18 Nas palavras de Franco Del Pozo (2000, p. 48-49): "O direito à vida é dependente do direito humano ao meio ambiente." 19 É a preocupação visível em algumas constituições nacionais: Argentina (Art. 41-43), Brasil (arts. 23, V e VII, 170, VI, 216 e 225), Paraguai (arts. 7, 8 e 268) e Chile (art. 198).

20 Ampliar o conceito e qualidade do meio ambiente sano em Gordillo (2007, p. VI-11-12); Silva (1995, p. 1-4) e Sirvinskas (2010, p. 103).

21 Ratificou-se, nesse sentido, instrumentos de proteção de águas doces e mar, como a Convenção de Londres para a prevenção de contaminação do mar em 12 de maio de 1954, e outros atinentes ao meio ambiente de qualidade, como, a Declaração Universal dos Direitos do Homem (arts. $3^{\circ}$ e 251) e a Declaração de Estocolmo (Princípio 1 e 13).

22 Veja-se o marco histórico do Direito internacional do meio ambiente realizado por Figueiredo (2009, p. 56-58). 
Dentro desse cenário evolutivo, a atual Administração Pública é inquestionavelmente uma compradora potencial. ${ }^{23}$ Assim, sua condição de influenciar o mercado, no que diz respeito à singular valoração do produto ecologicamente equilibrado, seja porque pode exigir características básicas de menor agressão ao meio ambiente, seja pela adoção de políticas de redução de compras e consumos desmedidos.

Nesse sentido, uma das formas de atuar é utilizar critérios objetivos tratando de maneira equitativa todos os concorrentes, mas para que isso ocorra é necessário que haja uma melhoria e modernização no sistema de compras públicas, pois o gestor público, a priori, é livre para escolher o objeto do contrato. Daí porque se deve atender a legislação pertinente no que se refere ao procedimento de adjudicação para que não ocorram restrições entre os concorrentes, afastando a competitividade ou impedindo a participação de qualquer deles.

Não é raro se ter notícias sobre a incineração de remédios que estão fora da validade, gerando resíduos, afetando sobremaneira o meio ambiente, bem como a despesa pública. Isto resulta de uma compra desnecessária, na medida em que não houve de fato uma análise de sua efetiva utilidade naquele momento ou até mesmo dos requisitos mínimos de qualidade do produto em relação ao benefício que poderia proporcionar o que decerto gerou defasagem, implicando no seu vencimento e consequente inutilidade.

Dentre outras aquisições, pode-se acrescentar aquela relativa à merenda escolar, indicando aos ofertantes quais os produtos ecologicamente adequados, evitando o uso de toxinas, além de oferecer maior valor nutritivo. Com essa medida, haveria um incentivo do governo no que concerne à produção de produtos menos tóxicos e agressivos ao meio ambiente.

Devido a gama de bens e serviços que instrumentalizam o funcionamento da máquina administrativa, é muito amplo o campo para a racionalização das compras, ${ }^{24}$ através de políticas públicas direcionadas, no sentido de priorizar o meio ambiente para que haja um entorno ambiental saudável.

No escopo de obter o êxito, é necessário que haja um conhecimento sobre o que é um produto ou serviço ecologicamente aceito, sendo necessário realizar uma pesquisa de mercado, verificando quais as implicações ambientais acerca da utilização de determinado componente e como administrar se inevitável sua aquisição.

23 As contratações públicas utilizam elevado percentual de $16,6 \%$ do produto interno bruto (PIB) na América Latina, movimentando R \$ 62,1 bilhões em 2014, cuja grande maioria, 92,41\% do total dos contratos celebrados com as MPE. Cf.. Ministério do Planejamento (2018). 
Assim, é importante a existência de uma equipe interdisciplinar composta de técnicos especializados que irão participar do processo de aquisição, com agentes responsáveis pelo controle de qualidade existente no mercado, até porque quando se quer chegar ao preço médio (base para a Administração Pública), pode-se trabalhar, aliando a qualidade do que vai ser adquirido.

Ademais, deve ser levado em consideração que além da compra ecológica, a Administração Pública pode e deve adotar métodos operacionais de redução de compra, assim, é fundamental comprar produto de boa qualidade, como forma de reduzir os impactos no meio ambiente. O produto de má qualidade tem uma tendência natural de vida útil curta, tendo que ser substituído várias vezes, ocasionando danos, posto que serão descartados. Também comprando menos é um instrumento essencial no combate a poluição, para tanto, é essencial comprar o que de fato necessita e de forma sustentável.

Saber comprar menos é uma questão de educação e conscientização do que precisamos. As compras no setor privado, na maioria das vezes, atendem à eficiência ${ }^{25} \mathrm{e}$ eficácia na relação qualidade e custo. Estas, por não estarem submetidas aos rigores licitatórios, tornam possíveis as aquisições fraudulentas? Será somente isso? Em realidade, esse panorama vem se modificando com o formato eletrônico de aquisição, onde há lances de preços com mais transparência e publicidade. Factível a uma participação infinita de ofertantes, permite-se comprar pelo melhor preço, sem esquecer a qualidade, esta extremamente importante às suas variantes. No entanto, este meio não abrange todas as necessidades de compras públicas, ainda é restrita a determinado tipo de produto/serviço. Todavia é um avanço. Assim, o procedimento eletrônico serviria como parâmetro no qual se examinaria os preços praticados no âmbito da Administração Pública.

O que se deve ter em mente para a efetividade da aquisição pública é a modernização do processo de aquisições, primando pelo melhor preço na nova versão, ou seja, englobando a vida útil e a menor agressividade ao ambiente. ${ }^{26}$ Desse modo, ao definir sua necessidade, indicaria, por exemplo, os resultados almejados, demonstrando que o desempenho ambiental do produto ou serviço a ser contratado é de suma importância. Aliás, a proposta mais vantajosa, nem sempre será a melhor aquisição, como já ficou esclarecido alhures. Pelas impropriedades advindas de uma má compra, os prejuízos são imensuráveis sejam no nível de custo ou no de degradação ambiental. 
De fato, poderia ser criado um banco de dados de padronização onde seriam depuradas as qualificações dos produtos, em uma espécie de coleção de dados organizados de maneira unificada e simplificada. Porém, com esse cadastro, o formato clássico de comprar estaria comprometido. Contudo, no tocante às obras, o procedimento usual continuaria em vigor, em virtude das peculiaridades do serviço a ser executado.

Nas obras e serviços de engenharia, a própria legislação pode exigir que haja um projeto básico de impacto ambiental, devendo atender o mínimo de requisitos capazes de proporcionar menor índice de agressividade ao meio ambiente com o menor custo na edificação. Nesse tipo de serviço devem-se levar em conta os materiais menos nocivos ao ambiente ${ }^{27}$ tomando-se em consideração o volume de resíduos que serão eliminados e a quantidade de materiais que poderão ser reciclados.

Imperioso observar que dentre as possíveis variantes à disposição da Administração Pública, é essencial que os gestores públicos implementem políticas ambientais educacionais voltadas tanto para utilização dos produtos e serviços públicos, como para a escolha do objeto a ser adquirido/contratado para não incorrer em vícios.

As novas abordagens da Administração Pública em prol de medidas protetivas do meio ambiente desafiam os ofertantes a buscaram soluções técnicas inovadoras. Outro fator bastante importante é a possibilidade de eliminar fornecedores que tenham infringido leis ou normas ambientais.

Por tais razões, a supranacionalidade ${ }^{28}$ se vincula à compra ecológica para permitir uma nova definição do mercado através da adequação dos custos frente aos critérios ecológicos para monitorar o desempenho de produtos em face da matéria prima, fontes, métodos, e ainda, meios que impeçam um volume de resíduos e a nocividade ambiental.

A ideia de sustentabilidade ${ }^{29}$ reside na qualidade de vida através de fatores de seleção ecológica que permitam a racionalidade na utilização dos recursos e a reciclagem, prévia qualificação ambiental do produto.

Nesse sentido, busca a responsabilidade ambiental pela utilização de recursos naturais que alcance a manutenção do ecossistema e proporcione uma menor agressão à natureza, como por exemplo, uso de energia solar, reutilização da água, pavimentação com asfalto ecológico e outros.

27 Atentar ao princípio jurídico supranacional da proteção da vida, integridade das pessoas humanas frente a contaminação do meio ambiente, ilustrado em Gordillo (2007, p. III-10).

28 Segundo Gordillo (2007, p. II-15-16): “O caráter supranacional é o caminho do futuro” (tradução própria).

29 Observem-se a título exemplificativo alguns marcos supranacionais do meio ambiente: Agenda 21, Convenção Quadro das Nações Unidas sobre Mudança do Clima, Convenção de Biodiversidade e o Protocolo Florestal. 
A supranacionalidade advinda da integração ambiental permite que a Administração Pública alcance suas prioridades aquisitivas promovendo uma participação em busca da melhoria da qualidade de vida, reduzir desperdícios e custos. Por esse formato, permite-se, por exemplo, a formação de funcionários e cidadãos ambientalmente responsáveis, e, que não pairem dúvidas que as ações ambientalmente corretas alcançam economia a longo prazo, e por essa atitude consciente importa numa licitação sustentável em busca de resultados voltados à qualidade do meio ambiente.

Trata-se de pequenos ajustes às licitações existentes para adequação e qualificação dos produtos a serem adquiridos em cumprimento às normas supranacionais que fazem valer o uso sustentável e racional dos recursos públicos, permitindo uma vida mais equilibrada do ponto de vista ecológico.

A aquisição ecológica também denominada como licitação sustentável ${ }^{30}$ ou compra ambientalmente amigável ou eco aquisição implica em considerar a responsabilidade do consumidor pela proteção da saúde, danos ambientais e qualidade do produto para comprar somente o que for realmente necessário, evitando aquisição de produtos supérfluos causadores de algum tipo de impacto ambiental. ${ }^{31}$

A aquisição ecológica é um formato de respeito ao meio ambiente e à cidadania que impõe à Administração Pública o cumprimento dos mandamentos supranacionais firmados em por países signatários, como exemplo, os compromissos ambientais das diretivas da União Europeia. $^{32}$

O que se deseja é a adequação dos processos de licitação existentes sob enfoque ambiental com o ensejo de minimizar as necessidades de compra e reduzir os custos em uma aquisição de produtos sustentáveis. A exemplo da utilização de produtos de limpeza não tóxicos, sistema de iluminação com conservação do ambiente, cartuchos de impressoras que produzam menos resíduo tóxico e etc.

A ideia da aquisição ecológica é efetivar a compra pública através do exemplo para adquiri-los promovendo incentivos ambientais e influenciando o mercado. (COMUNIDAD EUROPEIA, 2005, p. 5). Daí a importância da adequação da atual concepção de que suprir as necessidades públicas e simplesmente comprar aquilo que se necessita sem incluir critérios

30 Ampliar o significado do termo licitação sustentável em Clement (2003).

31 V. Lei 8.666/1993. Art. $6^{\circ}$. IX - Projeto básico - conjunto de elementos necessários e suficientes, com nível de precisão adequado, para caracterizar a obra ou serviço, ou complexo de obras ou serviços objeto de licitação, elaborado com base nas indicações dos estudos técnicos preliminares, que assegurem a viabilidade técnica e o adequado tratamento do impacto ambiental do empreendimento [...]. (BRASIL, 2018b).

32 V. Diretivas 2004/17 e 2004/18 da Comunidade Europeia. 
ambientais ou pensar nos riscos ecológicos. Deve-se aumentar a consciência ambiental ${ }^{33}$ de funcionários e da coletividade em geral.

Em verdade, não basta comprar o que a Administração Pública necessita. É necessário fazê-lo pensando no aprimoramento ecológico. Por exemplo: veículos com baixa emissão de gases, edifícios públicos com desempenho energético, ${ }^{34}$ adquirir produtos de limpeza sem substância perigosa, alimentos advindos de fontes orgânicas, diminuir gastos com papel, etc.

Na continuação se abordará os aspectos da gestão temerária, através da análise, detecção e formato da corrupção, assim como algumas das praticas corruptas que são comuns nas licitações.

\section{APORTE CONCLUSIVO}

Traçar o regime jurídico da contratação pública, a partir do estudo de sua expressão doutrinária até sua dogmática, é estabelecer a natureza jurídica dos institutos pertinentes ao assunto. Ademais, conforme notas introdutórias, esta pesquisa foi elaborada com o escopo de analisar a atuação da Administração Pública perante as formas atuais de aquisição pública na perspectiva do planejamento, adequação do produto a sua utilidade, previsibilidade orçamentária e da aquisição ecológica coma vistas a uma análise que garantam eficiência administrativa e a devida obediência às normas alusivas.

O estado em sua evolução busca a satisfação das necessidades da comunidade, transformando-se para alcançar maior eficiência na prestação de serviços públicos. Em epítome, a licitação deve garantir o estabelecimento de critérios justos e igualitários quanto à eleição dos licitantes por meio do planejamento e da aquisição sustentável.

Por tais razões da analise realizada podemos elencar as seguintes conclusões:

1. As normas licitatórias elaboradas com a finalidade precípua de resguardar o princípio da igualdade e economicidade possuem, entre outros ensejos planejados, como selecionar a proposta mais vantajosa e evitar o superfaturamento de objetos e serviços licitados, este resultado da privação de controle e transparência que disciplinam as aquisições públicas.

2.O planejamento eficaz é muito promissor devido a sua rapidez, transparência e efetividade prática, compatíveis com uma administração democrática, séria, ética e sem 
burocracia. Sob a influência dos direitos fundamentais poderiam suprimir ou sanar carências para que a licitação tenha mais operatividade, credibilidade e amplitude.

3.Impõe-se ao setor público a economicidade, o princípio da eficiência na contratação para proibir o mau uso e desperdício do dinheiro público. Vale recordar que a Administração Pública está jurídica e moralmente obrigada a adotar a solução mais eficaz e econômica com obediência da previsibilidade orçamentária para a satisfação do interesse público e da sociedade.

4. A compra ecológica permite a incorporação de critérios supranacionais para a preservação do meio ambiente. ${ }^{35}$ Será possível monitorar o desempenho dos produtos desde a fase de extração da matéria até a elaboração, tomando medidas extremas para que as fontes, métodos e processos sejam sustentáveis ecologicamente e impeçam um grande volume de resíduos e o dano ambiental. Por isso nas licitações deverão ser incluídos os materiais menos nocivos para o ambiente além da analise da quantidade de materiais que poderá ser reciclado.

5. Requere-se uma promoção da maturidade do relacionamento entre a Administração Pública, o provedor e o cidadão para que possam discutir aquilo que é melhor para o interesse público. Um vínculo maduro possibilitaria a ampliação participativa através de audiências públicas prévias às compras governamentais. Estas são importantes medidas de combate à corrupção, a qual impede, direta ou indiretamente, o desenvolvimento dos países.

6. É necessário adotar medidas efetivas no âmbito interno para alcançar instrumentos de eficiência e legitimidade da função administrativa, assim como garantir plenitude de direitos dos cidadãos. Isto possibilitará um melhor desempenho na aquisição de bens e serviços públicos por parte dos órgãos estatais. O devido planejamento possibilitará a elucidação de possíveis lacunas na interpretação fática e impedirá uma gestão temerária que perturbe o sistema jurídico.

Desde a respectiva abordada, podemos ver que o tema não se esgota neste estudo sobre regime geral da licitação, já que requer uma diligência constante e uma profunda análise das demandas sociais, para assim poder solucionar os conflitos dos cidadãos e da Administração Pública.

\footnotetext{
${ }^{35}$ Por exemplo: a Declaração de Estocolmo, a Declaração do Rio, Agenda 21, a Convenção sobre a Diversidade Biológica, a Convenção Quadro das Nações Unidas sobre Mudanças Climáticas, a Convenção de Viena para a Proteção da Camada de Ozônio.
} 


\section{REFERÊNCIAS}

ALTOUNIAN, Cláudio Sarian. Obras públicas: licitação, contratação, fiscalização e utilização, $2^{a}$. ed., Brasília: Fórum, 2009.

ANTUNES, Paulo de Bessa. Direito ambiental. 12ª ed., Rio de Janeiro: Lumen Juris, 2010.

BALEEIRO, Aliomar. Uma introdução à ciência das finanças. 15a . ed., Rio de Janeiro: Renovar, 1977.

BEZERRA FILHO, João Eudes. Contabilidade pública: teoria, técnica de elaboração de balanços, $3^{\text {a }}$. ed., Brasília: Campus, Rio de Janeiro, 2007.

BIDERMAN, Rachel. Guia de Compras Públicas Sustentáveis. ICLEI - Governos Locais pela Sustentabilidade, Uso do poder de compra do governo para a promoção do desenvolvimento sustentável. 2a . ed., Rio de Janeiro: FGV, 2008.

BIELSA, Rafael. Principios de derecho administrativo. Buenos Aires: Universidad Nacional del Litoral, 1942.

BLANCHET, Luiz Alberto. Licitação: o edital à luz da nova lei, 2a . ed., Curitiba: Juruá, 1994.

Roteiro prático das licitações. 6a . ed., Curitiba: Juruá, 2003.

BRASIL. Lei complementar $\mathbf{n}^{\mathbf{0}}$ 101/2000. Disponível: http://www.planalto.gov.br/ Acesso em 01.04.2018.

BRASIL. Lei no 8.666/1993. Disponível: http://www.planalto.gov.br/ Acesso em 01.04.2018.

BREWER-CARÍAS, Allan R. Derecho administrativo. t. I e II, Bogotá: Universidad Externado de Colombia, 2006.

CAPUTI, Maria Claudia. La ética pública. Buenos Aires: De palma, 2000.

CARVALHO FILHO, José dos Santos. Manual de direito administrativo. $28^{\text {a }}$. ed., Rio de Janeiro: Lúmen Juris, 2015.

CARVALHO, Antônio César Leite de; SANTANA, José Lima. Direito ambiental brasileiro em perspectiva. Curitiba: Juruá, 2009.

CASSAGNE, Juan Carlos. Derecho administrativo. $\mathrm{t}$ I e II, $8^{\text {a }}$. ed., Buenos Aires: AbeledoPerrot, 2006.

CLEMENT, Simon e outros. The Procura+ manual, a guide to cost-effective sustainable public procurement. Munich: Ökum Verlag, 2003. ICLEI, Procura+, Sustainable procurement campaign website. Disponível em <www.procuraplus. org $>$. Acesso em 01.04.2018.

COMUNIDAD EUROPEIA. Manual de contratos públicos ecológicos. Luxemburgo:

Serviço de publicações oficiais, 2005.

DALLARI, Adilson Abreu. Aspectos jurídicos da licitação. $7^{\mathrm{a}}$. ed., São Paulo: Saraiva, 2007.

DURÃO, Pedro. Licitación pública. Curitiba: Juruá, 2015. 
2016 .

Técnica de parecer: como fazer um dictamen jurídico, $2^{\text {a }}$. ed., Curitiba: Juruá,

_ Convênios e consórcios públicos: gestão, teoria e prática, $5^{\text {a }}$ ed., Juruá: Curitiba, 2017.

Transformaciones del derecho administrativo. Buenos Aires: Livro \& Bites, 2008.

FIGUEIREDO, Guilherme José Purvin de. Curso de direito ambiental. $3^{\mathrm{a}}$. ed., Curitiba: Letra da lei, 2009.

FRANCO DEL POZO, Mercedes. EI derecho humano a un medio ambiente adecuado. Bilbao: Universidade de Deusto, 2000.

GORDILLO, Agustín. Tratado de derecho administrativo. $9^{a}$. ed., t. II, La defensa del usuario y del administrado. Buenos Aires: Fundación de Derecho Administrativo, 2009.

GORDILlO, Agustín e outros. Derechos Humanos. 6a . ed., Buenos Aires: Fundação de Direito Administrativo, 2007.

GORDILLO, Agustín et al. Contratos administrativos: regímenes de pago y actualización. Buenos Aires: Astrea, 1988.

LASO, Enrique Sayagues. La licitación pública. Montevidéu: B de F, 2005.

MINISTÉRIO DO PLANEJAMENTO. Contratações públicas. Disponível:

http://www.brasil.gov.br/governo/2015/03/ contratacoes-publicas. Acesso em 01.04.2018

OLIVEIRA, Pedro Rocha de. Obras públicas: tirando suas dúvidas. Belo Horizonte: Fórum, 2010.

RIVERO, Jean. Direito administrativo. Coimbra: Almedina, 1981.

ROSA JÚNIOR, Luis Emygdio. Manual de direito financeiro e direito tributário. $11^{\mathrm{a}}$. ed., Rio de Janeiro: Renovar, 1977.

SILVA, José Afonso da. Direito ambiental constitucional. 2a . ed., São Paulo: Malheiros, 1995.

SIRVINSKAS, Luis Paulo. Manual de direito ambiental. 8a . ed., São Paulo: Saraiva, 2010.

TRINDADE JÚNIOR, Francisco Ulisses da. "Planejamento das Licitações, o planejamento das licitações públicas como fator de eficiência” en BDJur, Brasília, DF, 22. jan. 2010.

Tribunal de Contas da União. Licitações e contratos, orientações e jurisprudência do TCU. 4a . ed., Brasília, TCU, 2010. 